\title{
A Reliability Analysis to Runway Incursion Based on Improved CREAM
}

\author{
Gao Yang \\ National Key Laboratory of Air Traffic Operation- \\ Safety Technology \\ Research Institute of Civil Aviation Safety, CAUC \\ Tianjin China
}

\author{
Bian Ziqi \\ National Key Laboratory of Air Traffic Operation- \\ Safety Technology \\ Research Institute of Civil Aviation Safety, CAUC \\ Tianjin China \\ e-mail:510259692@qq.com
}

\begin{abstract}
Human factor is one of the most important reasons causing runway incursion event happened. On the basis of statistics analyzing the existing research about runway incursion human factor causes, this paper builds a key human factor influencing runway incursion and proposes a process of controllers and pilots interaction on influencing runway incursion with the characteristic of dynamic, interaction and closed-loop. Then an improved CREAM model method is applied to predict the reliability of this process. The final conclusion shows the importance of controllers and pilots interaction that in a real situation influencing runway incursion, not only the consideration on actual occurred runway incursion event is needed, the interaction between controllers and pilots also needs to be concerned. This paper brings a new idea and way for further risk assessment of runway incursion based on human factors. Besides, considering the reliability of controllers and pilots interaction, how to improve its existing interaction mode will be the next key work.
\end{abstract}

Keywords-runway incursion; human factor; interaction; CREAM; reliability (key words)

\section{INTRODUCTION}

As the fast development of Chinese civil aviation transportation, safety is becoming more and more significant. Rapid increase of the number of aircraft and flight leads to civil airports serious busyness. As one of the three large system of civil aviation transportation, whether can the safety of airport be guaranteed will play a vital part to the regular, safe and continuous operation of civil aviation transportation. Runway incursion is a kind of unsafe event influencing airport safety and inducing aircraft collision accident. A typical case is the most catastrophic air crash in history-the Tenerife air crash, which two Boeing 747 airliner collides each other under high speed on runway kills 583 persons. Runway incursion is used as a terminology, but not a unified definition has been developed for it yet among the civil aviation industry. ICAO defines runway incursion as: a condition where happens in an airport that any aircraft, vehicle or staff incorrectly accesses the ground area being used by the take-off or landing plane. From the official data of Federal Aviation Administration, only in financial year 2013, there are 1241 runway incursion events happened in all American airports, and the incidents and accidents caused by the error of controllers and pilots are total $1026{ }^{[1]}$.So it is clearly that human factor is one of the major reasons leading to runway incursion.

Now, some existing research shows communication, air traffic control, pilots and airport ground vehicle drivers are the 4 key elements to cause runway incursion ${ }^{[2]}$. And in the air traffic control, controllers forgetting, incorrectly coordinating and wrongly communicating to pilots is also the important reasons leading to runway incursion ${ }^{[3]}$. The above elaborates the human factor and its type of causing runway incursion but involves no quantitative possibility or reliability of human error. Xu Gui-mei tries to establish a runway incursion risk assessment model based on human reliability ${ }^{[4]}$, and the model works out pilot and controller each error probability on runway incursion prevention. Zhao Zhen-wu applies an improved CREAM to analyze the reliability between controller and pilot ${ }^{[5]}$. Therefore this paper proposes a process of controllers and pilots interaction influencing runway incursion, and improves the CREAM model method to predict the reliability of this process.

\section{BUILDING THE PROCESS OF CONTROLLERS AND}

\section{PILOTS INTERACTION INFLUENCING RUNWAY INCURSION}

The controllers and pilots interaction is a dynamic process of utilizing correspondence and radio navigation technology to monitor, adjust and control aircraft situation and operation. This process includes controller issuing instruction to conduct plane, pilot executing instruction to operate plane, and each other judging result and feeding back information. This is also a closed-loop process between controllers and pilots, such as Fig .1.

Then considering the characteristic of dynamic and closed-loop about controllers and pilots interaction process, combining the control tower's work content and procedure with flight operation among airport runway and taxiway, this paper builds the process of controllers and pilots interaction influencing runway incursion as follow:

- Controller monitors the dynamic of runway and taxiway. This process mainly is controller realizing the situation of each runway, taxiway, aircraft and its operation by radar or eye.

- Controller communicates and contacts with pilot. Controller generally uses transceiver to communicate with pilot to obtain information of aircraft condition and pilot's intention. 
- Controller judges and discovers potential runway incursion hazard, according to the runway site changing and controller's own experience.

- Controller develops the coordinate scheme. If hazard is identified, controller will establish a coordinate scheme according to airport control manual or plan.

- Controller issues coordination instruction and pilot operates plane to adjust according to the instruction.

- Controller and pilot checks aircraft operation situation, feedbacks result and gathers information.

And this process can also be simplified as Fig .2:

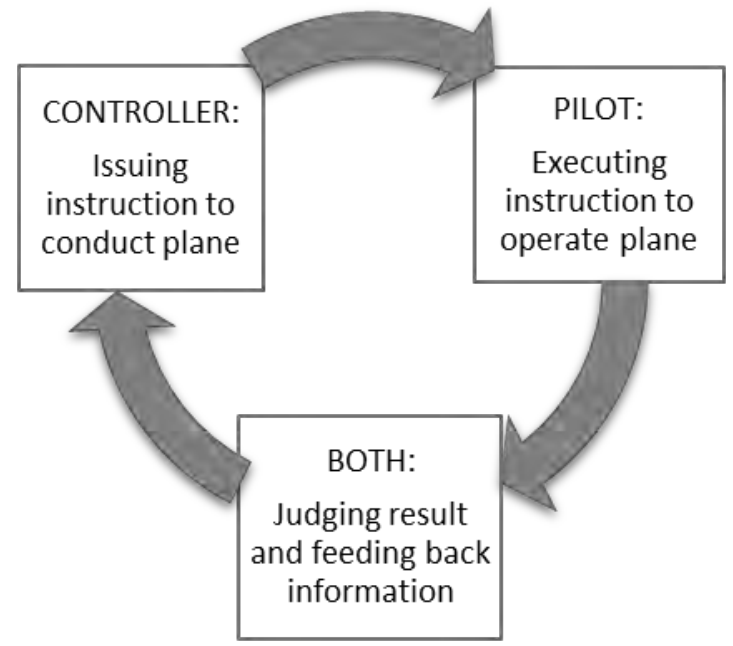

Figure 1. The dynamic and closed-loop process of controllers and pilots interaction.

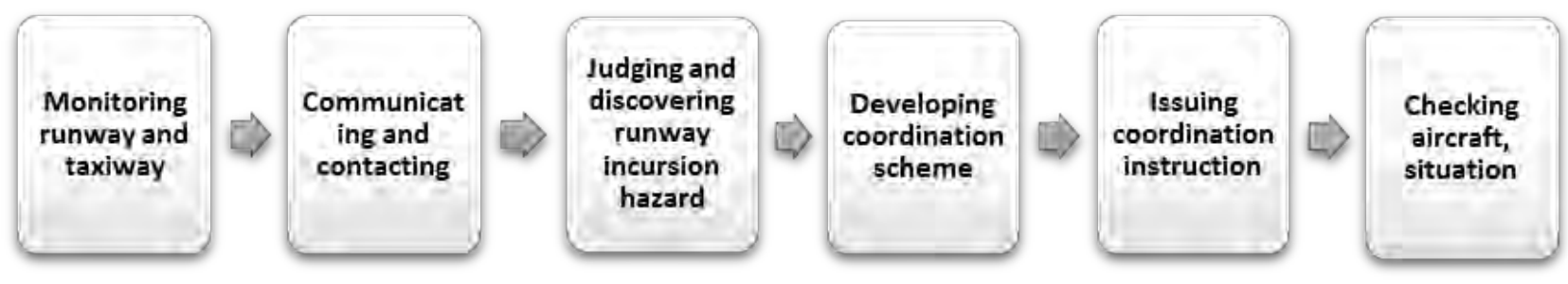

Figure 2. The process of controllers and pilots interaction influencing runway incursion

III. THE IMPROVED CREAM AND ITS USAGE ON THE PROCESS OF CONTROLLERS AND PILOTS INTERACTION

\section{A. An Improvement to CREAM Model Method}

Cognition reliability and error analysis method, namely CREAM, is often used for studying human reliability ${ }^{[6]}$. Its superiority is to combine human behavior performance with situation or working circumstance of human actual location. Through analyzing human work task and setting the event sequence, CREAM identifies human different cognition behavior in each event or task and corresponding cognition function. Then CREAM determines the most happening error mode of each human cognition function and corresponding basic error probability value. The basic error probability value of cognition function is also called as CFP Calibration. Finally, after the CFP Calibration is corrected by the actual situation or working circumstance, human reliability can be predicted.

CREAM presents 15 types of cognition behavior and 4 types of cognition function (including observation, explanation, plan and execution), every cognition behavior corresponds to its different cognition function. Details can be referred in TABLE I ${ }^{[7]}$, the matrix of cognition behavior and function.
TABLE I. THE MATRIX OF COGNITION BEHAVIOR AND FUNCTION.

\begin{tabular}{|ccccc|}
\hline \multirow{2}{*}{ Behavior Type } & \multicolumn{4}{c|}{ Cognition Function } \\
\cline { 2 - 5 } & observation & Explanation & plan & Execution \\
\hline Coordination & & & $\sqrt{ }$ & $\sqrt{ }$ \\
Correspondence & & $\sqrt{ }$ & $\sqrt{ }$ \\
Comparison & & $\sqrt{ }$ & $\sqrt{ }$ & \\
Diagnosis & & $\sqrt{ }$ & $\sqrt{ }$ & \\
Evaluation & & $\sqrt{ }$ & & \\
Execution & & & $\sqrt{ }$ & $\sqrt{ }$ \\
Identification & & $\sqrt{ }$ & \\
Preservation & & & & \\
Surveillance & $\sqrt{ }$ & & $\sqrt{ }$ \\
Observation & $\sqrt{ }$ & $\sqrt{ }$ & \\
Plan & & $\sqrt{ }$ & \\
Record & & $\sqrt{ }$ & & \\
Adjustment & $\sqrt{ }$ & $\sqrt{ }$ & \\
Scan & $\sqrt{ }$ & & & \\
Verification & $\sqrt{ }$ & & & \\
& & & & \\
\hline
\end{tabular}


For the 4 kinds of cognition functions, there are also different levels of cognition function error mode due to the diverse situation or working circumstance. For instance, observation has 3 types of error mode, such as observation target error, identification error and no observation. These basic error probability values (CFP Calibration) are respectively $0.001,0.07$ and 0.07 . Details of other cognition functions and their CFP Calibrations can also be seen in TABLE II ${ }^{[8]}$.

The matrix of cognition behavior and function of CREAM is applicable to general situation or working circumstance. Combining the process of controllers and pilots interaction built by this paper, the original matrix needs to be improved. As the communication between controllers and pilots involves the criterion, accuracy and coherence of aviation speaking language as well as the comprehension to each other's intention, it is not accurate that the cognition behavior of correspondence only refers to the cognition function of execution. But after adding a cognition function of explanation in the cognition behavior of correspondence, this is more conformable to the reality of controllers and pilots communication, which is can be mentioned as TABLE III.
TABLE II. THE COGNITION FUNCTION ERROR MODE AND CFP CALIBRATION

\begin{tabular}{|c|c|c|}
\hline $\begin{array}{c}\text { Cognition } \\
\text { Function }\end{array}$ & Error Mode & CFP Calibration \\
\hline \multirow{4}{*}{ Observation } & O1 Observation target error & 0.001 \\
\cline { 2 - 3 } & O2 Identification error & 0.07 \\
\cline { 2 - 3 } & O3 No observation & 0.07 \\
\hline \multirow{4}{*}{ Explanation } & I1 Diagnosis failure & 0.2 \\
\cline { 2 - 3 } & I2 Decision fault & 0.01 \\
\hline \multirow{3}{*}{ Plan } & I3 Explanation delay & 0.01 \\
\cline { 2 - 3 } & P1 Wrong priority & 0.01 \\
\hline \multirow{4}{*}{ Execution } & P2 Improper plan & 0.01 \\
\cline { 2 - 3 } & E1 motion manner error & 0.003 \\
\cline { 2 - 3 } & E2 motion time error & 0.003 \\
\cline { 2 - 3 } & E3 motion purpose error & 0.0005 \\
\cline { 2 - 3 } & E4 motion order error & 0.003 \\
\hline
\end{tabular}

TABLE III. THE IMPROVED COGNITION FUNCTION AND ERROR MODE ON THE PROCESS OF CONTROLLERS AND PILOTS INTERACTION INFLUENCING RUNWAY INCURSION

\begin{tabular}{|c|c|c|c|c|c|c|c|c|}
\hline \multirow{2}{*}{$\begin{array}{c}\text { Event } \\
\text { Sequence }\end{array}$} & \multirow{2}{*}{ Task } & \multirow{2}{*}{$\begin{array}{l}\text { Cognition } \\
\text { Behavior }\end{array}$} & \multicolumn{4}{|c|}{ Cognition Function } & \multirow{2}{*}{$\begin{array}{l}\text { Error } \\
\text { Mode }\end{array}$} & \multirow{2}{*}{$\begin{array}{c}\text { CFP } \\
\text { Calibration }\end{array}$} \\
\hline & & & Observation & Explanation & Plan & Execution & & \\
\hline 1 & $\begin{array}{l}\text { Monitoring runway and } \\
\text { taxiway }\end{array}$ & Observation & $\sqrt{ }$ & & & & $\mathrm{O} 2$ & 0.07 \\
\hline 2 & $\begin{array}{l}\text { Communicating and } \\
\text { contacting }\end{array}$ & Correspondence & & & & $\sqrt{ }$ & I1 & 0.2 \\
\hline 3 & $\begin{array}{l}\text { Judging and discovering } \\
\text { runway incursion hazard }\end{array}$ & Diagnosis & & $\sqrt{ }$ & $\sqrt{ }$ & & I3 & 0.01 \\
\hline 4 & $\begin{array}{l}\text { Developing coordination } \\
\text { instruction }\end{array}$ & Plan & & & $\sqrt{ }$ & & $\mathrm{P} 2$ & 0.01 \\
\hline 5 & $\begin{array}{l}\text { Issuing coordination } \\
\text { instruction }\end{array}$ & Execution & & & & $\sqrt{ }$ & E3 & 0.0005 \\
\hline 6 & Checking aircraft situation & Verification & $\sqrt{ }$ & $\sqrt{ }$ & & & $\mathrm{O} 3$ & 0.07 \\
\hline
\end{tabular}

represents for the new added cognition function to cognition behavior after improvement

\section{B. Identifying Cognition Function Error Mode of the Process of Controllers and Pilots Interaction}

- Controller monitors runway, taxiway and aircraft by radar or eye, which is a cognition behavior of observation. And the most happening error of it is identification error of runway, taxiway or aircraft codename, so its error mode is $\mathrm{O} 2$.

- The irregularity and misunderstanding of speaking language often happens in a correspondence behavior, so the error mode is I1.
- Judging and discovering potential runway incursion hazard is a diagnosis process of controllers according to his consciousness or experience. But due to some reason such as fatigue or attention stagnating, controller often cannot explain to pilot timely, so the error mode should be I3.

- During the process of developing coordination plan, because of the time shortage and the situation complexity, controller commonly hard to develop an optimal coordination scheme in a short time, so this error mode is often $\mathrm{P} 2$. 
- When issuing coordination instruction, the most occurred error mode between controller and pilot is E3, such as issuing instruction to a wrong aircraft or aircraft entering a wrong taxiway etc.

- At the last feedback process of verifying aircraft operation situation, controller is more apt to forget, not recheck or not re-monitor aircraft due to lack of time, therefore error mode is O3. All above is also presented in TABLE III.

\section{The CFP Correction Influenced by the Real Situation or Woriking Circumstance}

After the CFP calibration has been determined, it is necessary to consider the influence to CFP calibration by actual situation or working circumstance, which is called the CFP correction. CREAM classifies human situation or working circumstance as 9 influence elements, which is called the common performance condition, shorted as CPC ${ }^{[9]}$. Each CPC has different practical level which can be appraised by some adjectives such as very effective, superior, appropriate and sufficient. Different CPC level generates 3 different kinds of influence to human performance including improvement, indifference or decrease. As the reaction extent of cognition function is different due to the diverse CPC level and human performance, CREAM presents different weight factor of cognition function under diverse CPC level and human performance.

This paper simulates an optimum of CPC level, such as TABLE IV ${ }^{[10]}$, then through the sequential multiplication to every weight factor of 4 cognition function under each $\mathrm{CPC}$ level and human performance, the total weight factors of each CFP calibration can be figured out. Finally, CFP correction can be arrived by the following relationship: CFP correction $=$ CFP calibration $*$ total weight factors, such as TABLE V.

\section{The reliability of the Process of Controllers and Pilots Interaction}

According to the following equation:

$$
\mathrm{P}=1-\prod_{i=1}^{6}(1-C F P i)
$$

$P$ represents the probability, $C F P_{i}$ is namely $\mathrm{CFP}$ correction. Then after the calculation, the result that under an optimum of CPC level, the error probability of the process of controllers and pilots interaction influencing runway incursion is $3.02 \times 10^{-2}$.

\section{TABLE IV. THE OPTIMUM CPC LEVEL AND COGNITION FUNCTION WEIGHT FACTORS.}

\begin{tabular}{|c|c|c|c|c|c|c|}
\hline \multirow{2}{*}{ CPC Name } & \multirow{2}{*}{ Level } & \multirow{2}{*}{$\begin{array}{l}\text { Influence to } \\
\text { Performance }\end{array}$} & \multicolumn{4}{|c|}{ Weight Factors } \\
\hline & & & Observation & Explanation & Plan & Execution \\
\hline $\begin{array}{c}\text { Completeness of } \\
\text { organization }\end{array}$ & Very effective & Improvement & 1.0 & 1.0 & 0.8 & 0.8 \\
\hline Working condition & Superior & Improvement & 0.8 & 0.8 & 1.0 & 0.8 \\
\hline $\begin{array}{c}\text { Completeness of HMI and } \\
\text { operation support }\end{array}$ & Supportive & Improvement & 0.5 & 1.0 & 1.0 & 0.5 \\
\hline Usability of plan & Appropriate & Improvement & 0.8 & 1.0 & 0.5 & 0.8 \\
\hline Simultaneous target & Below people's ability & Improvement & 1.0 & 1.0 & 1.0 & 1.0 \\
\hline Available time & Sufficient & Improvement & 0.5 & 0.5 & 0.5 & 0.5 \\
\hline Working time & Daytime (adjusted) & Insignificance & 1.0 & 1.0 & 1.0 & 1.0 \\
\hline $\begin{array}{c}\text { Sufficiency of training and } \\
\text { experience }\end{array}$ & $\begin{array}{c}\text { Sufficient and } \\
\text { experienced }\end{array}$ & Improvement & 0.8 & 0.5 & 0.5 & 0.8 \\
\hline $\begin{array}{c}\text { Cooperation quality of team } \\
\text { members }\end{array}$ & Very effective & Improvement & 0.5 & 0.5 & 0.5 & 0.5 \\
\hline
\end{tabular}

TABLE V. THE TOTAL WEIGHT FACTORS AND CPC CORRECTION

\begin{tabular}{|c|c|c|c|c|c|}
\hline Task & Cognition Behavior & $\begin{array}{c}\text { Error } \\
\text { Mode }\end{array}$ & CFP Calibration & $\begin{array}{c}\text { Total Weight } \\
\text { Factors }\end{array}$ & CFP Correction \\
\hline Monitoring runway and taxiway & Observation & O2 & 0.07 & 0.064 & 0.00448 \\
\hline Communicating and contacting & Correspondence & I1 & 0.2 & 0.1 & 0.02 \\
\hline $\begin{array}{c}\text { Judging and discovering runway incursion } \\
\text { hazard }\end{array}$ & Diagnosis & I3 & 0.01 & 0.1 & 0.001 \\
\hline Developing coordination scheme & Plan & P2 & 0.01 & 0.05 & 0.0005 \\
\hline Issuing coordination instruction & Execution & E3 & 0.0005 & 0.0512 & 0.0000256 \\
\hline Checking aircraft, situation & Verification & O3 & 0.07 & 0.064 & 0.00448 \\
\hline
\end{tabular}




\section{THE CONCLUSION}

The result shows that the error probability of controllers and pilots interaction is high. So in the real situation influencing runway incursion, not only the consideration on actual happened runway incursion event is needed, the interaction process between controllers and pilots also needs to be concerned. Therefore how to improve the existing the interaction mode between controllers and pilots will be the next step work.

This paper simulates an optimum of CPC level, which is generally uncommon in reality. There is also a problem about how to evaluate the real CPC level in a more objective and accurate way.

Besides, this paper makes an improvement of the matrix of cognition behavior and function aiming at the communication between controllers and pilots, which is an innovation to CREAM.

The process of controllers and pilots interaction built by this paper brings a new idea and way for further risk assessment of runway incursion based on human factors.

\section{REFERENCES}

[1] Runway Incursion Totals for FY 2013. Federal Aviation Administration Home. [2014-9-17].

http://www.faa.gov/airports/runway_safety/statistics/regional/?f $\mathrm{y}=2013$.
[2] Sun Jie. Research on the Risk Management of the Runway Safety in Airports[D]. Nanjing: Nanjing University of Aeronautics and Astronautics, 2009.

[3] Hou Wan-jun. The Human Factor in Runway Incursion[J] Merchandise and Quality: Theory Research, 2011, 12: 52-52.

[4] Xu Gui-mei, Huang Sheng-guo. Runway Incursion Risk Assessment Model Based on HRA[J]. Science Technology and Engineering, 2010, 10(19): 14-17.

[5] Zhao Zhen-wu, Zhang Wei. The Human Reliability Analyze between Controller and Pilot Based on Improved CREAM[J] Journal of Safety and Environment, 2013, 13(1): 185-187.

[6] Sun Rui-shan, Wang Xin. Application of Failure Probability of CREAM for Judgement and Decision Making in the Cockpit[J]. Journal of Safety Science and Technology, 2010, 6(6): 40-45.

[7] Xu Guimei. Research on Techniques of Risk Management for Airports Runway Accident[D]. Nanjing: Nanjing University of Aeronautics and Astronautics, 2010.

[8] Luo Jun, Jiang Ke-mi. Study of Runway Incursion Risk Evaluation Based on Human Cognitive Error[J]. Journal of Civil Aviation Flight University of China, 2013, 24(4): 31-34.

[9] Wang Yao, Shen Zu-pei. CREAM - the Second Human Factor Reliability Analysis Method[J]. Industrial Engineering and Management, 2005, 3: 17-20.

[10] Zhang Wei. Reserch on Collision Risk of Parallel Routes Model Based on Human Reliability[D]. Tianjin: Civil Aviation University of China, 2013. 